\title{
Management of tuberculosis of the uterine cervix in the University Hospital Center of Treichville
}

\author{
Dia J. M. ${ }^{1 *}$, Saki T. C. ${ }^{1}$, Kone Z. ${ }^{2}$, Koui S. ${ }^{3}$, Bohoussou P. E. ${ }^{1}$, \\ Diallo A. ${ }^{1}$, Guié P. ${ }^{1}$, S. Anongba ${ }^{1}$
}

\begin{abstract}
${ }^{1}$ Department of Obstetrics and Gynecology, University Hospital of Treichville, Abidjan, Côte d'Ivoire ${ }^{2}$ Department of Pneumology, University Hospital of Treichville, Abidjan, Côte d'Ivoire

${ }^{3}$ Department of Histopathology, University Hospital of Treichville, Abidjan, Côte d'Ivoire
\end{abstract}

Received: 18 November 2017

Accepted: 18 December 2017

\author{
*Correspondence: \\ Dr. Dia J. M., \\ E-mail: jmlaminedia@yahoo.fr
}

Copyright: (C) the author(s), publisher and licensee Medip Academy. This is an open-access article distributed under the terms of the Creative Commons Attribution Non-Commercial License, which permits unrestricted non-commercial use, distribution, and reproduction in any medium, provided the original work is properly cited.

\begin{abstract}
Genital tuberculosis is a rare entity which is classically presented with nonspecific signs posing diagnostic problems. We report the case of a young patient in genital activity, supported in our hospital for tuberculosis of the uterine cervix. She initially consulted for contact metrorrhagia and speculum examination had found an ulcerative budding cervix making suggest a cervical cancer. Finally, the histology of cervical biopsy confirmed the diagnosis of cervical tuberculosis and the patient was treated with anti-bacillary antibiotics. The evolution was favourable marked by declared healing after 6 months of treatment. The objective of this observation is to discuss the epidemiological, clinical and therapeutic characteristics of this affection.
\end{abstract}

Keywords: Tuberculosis, Uterine cervix-management

\section{INTRODUCTION}

The tuberculosis (TB) is an endemic disease of developing countries, caused by the presence of Kock's bacillus (BK) in the body. The HIV pandemic has revived interest of TB, increasing its incidence. ${ }^{1}$ The TB affects all the body tissues, but the lung disease remains by far the most common. In women, the extra lung localisations concern the genital system in about $5 \%$ of cases, with a small proportion of the cervical spine. ${ }^{2}$ These genital forms are typically manifested by nonspecific signs posing diagnostic problems.

Thus, the cervical tuberculosis which is a rare form of genital tuberculosis, will often manifest by signs similar to cervical cancer. We report a rare case of cervical tuberculosis (CTB) in a woman treated in our hospital with the objective to discuss the epidemiological, clinical and therapeutic characteristics of this affection.

\section{CASE REPORT}

Mrs. KM, 33-year-old woman, mother of 2 children, without a spouse, living in modest social conditions, has consulted for contact metrorrhagia. The interrogation has found in her history a notion of tuberculosis in her surrounding: her aunt with whom she lived in the same compound had pulmonary TB 2 years ago, treated and declared cured for about 1 year. Furthermore she never realized a cervical cancer or HIV screening examination. The contact metrorrhagia were preceded with an unexplored secondary amenorrhea of about 3 months (that she did not link to a pregnancy because her last sexual encounter dated back to more than a year earlier) 
and a loss of weight of about $8 \mathrm{~kg}$ in less than 2 months. The physical examination on admission noted an average general condition with a weight of $69 \mathrm{Kg}$ (her a usual weight was $77 \mathrm{Kg}$ and she appeared emaciated) and a temperature of $37^{\circ}$. The gynecological speculum examination found a red cervix of budding appearance, less bleeding on contact with whitish leucorrhoea at its internal orifice and a normal vaginal wall (Figure 1).

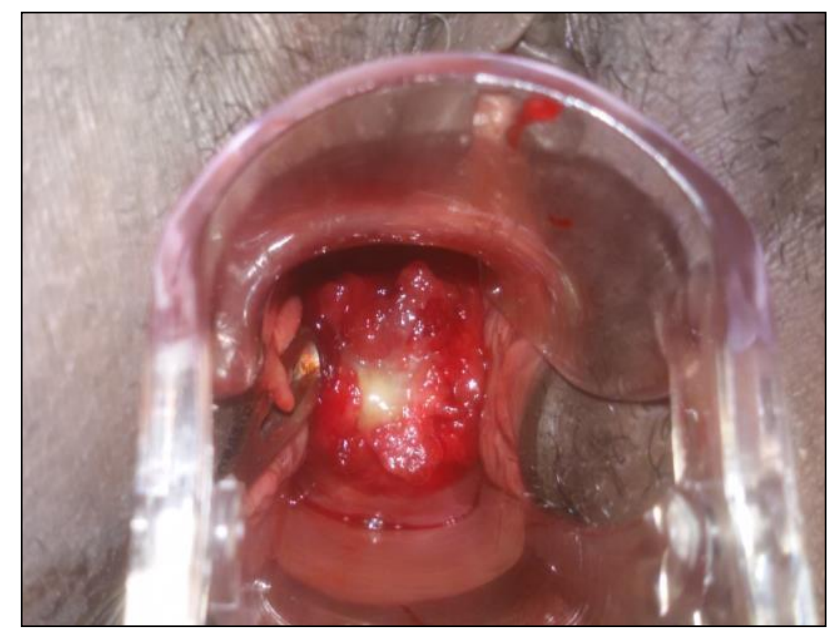

Figure 1: Speculoscopy showing a budding cervix with leucorrhoea at its internal orifice and a normal vaginal wall.

The vaginal touch found a non-friable firm and closed cervix, an uterus of normal size, normal appendices and red blood on the finger. The review of other devices (lung, mucocutaneous, splenoganglionnary, cardiovascular) was unremarkable. Face to this picture, we discussed as diagnosis a cancer or a TB of the cervix, and made a biopsy of the suspected lesion. Pending the outcome of histological biopsy, a biological test performed showed a mild anemia at $8.7 \mathrm{~g} / \mathrm{dl}$, a reversal of the leukocyte formula (with $78 \%$ lymphocytes), an IDR positive to the tuberculin, HIV serology negative. Finally, histology confirmed the diagnosis of CTB face to infiltrates lesions of gigantic cells with little caseous necrosis (Figure 2).

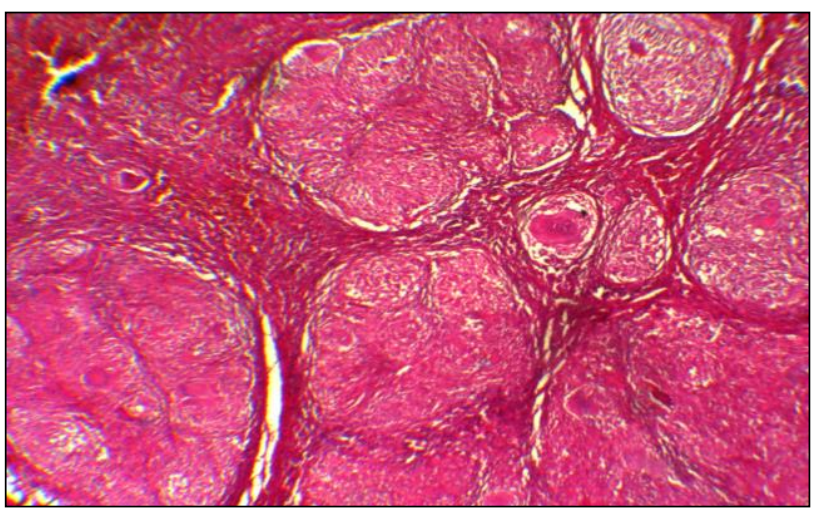

Figure 2: Optical magnification $\times 100$ showing Langhans cells.
The management was then multidisciplinary associating lung specialists and gynecologists. A general assessment was therefore asked: the lung and the thoracolumbar spine X-rays were normal; the uterus and its annexes were normal to the pelvic ultrasound. She benefited from a quadruple anti baccillary antibiotics for six months. The treatment was well tolerated, and the evolution was favorable. The general condition improved as early as the second week and the metrorrhagia stopped after two months of treatment. Then, the menses reappeared and the cervix became macroscopically normal, respectively, four and five months after the start of treatment. Three months after the end of treatment, the control visit and hysterosalpingography found no abnormalities.

\section{DISCUSSION}

\section{Epidemiological aspects}

TB is a public health problem, especially in poor countries where it is a rampant at an endemic state. In women, the CTB is a rare form and represents less than $8 \%$ of genital damage. ${ }^{3}$ In our service a first case was found about ten years ago. proving the rarity of this disease in our area. However, some authors believe that in low resource countries where $\mathrm{TB}$ is endemic, the cervical localisation could be underestimated due to under medicalization. ${ }^{4,5}$

The genital localisation of TB can be done at any age, but young patients in genital activity seem most exposed. ${ }^{1,2}$ Our patient was pauciparous, young (32 years old) and was exposed to the conditions of BK infection (modest social status, notion of tuberculosis in her surrounding).

Regarding the pathogenesis of infection of the cervix, the primary contamination is exceptional, and 2 mechanisms seem more frequent : either a direct attack through sex or a contamination through blood or lymphatic system. ${ }^{5}$ In the first case, a male having urogenital TB can directly infect the genital tract of his partner during unprotected sex. Also a male suffering from a lung TB using his saliva as a lubricant during sex can infect the genital tract of his unprotected partner. Regarding the second mechanism, a patient with extra genital TB (lung, bone) can secondarily infect her cervix through hematogenous or lymphatic tracts.

In our patient, the history of the disease does not allow us to determine the exact mechanism of the cervical contamination even if an infection throught sex seems unlikely.

\section{Symptomatology and diagnosis}

The clinical signs of TB are nonspecific and similar to those of cervical cancer. Indeed these 2 pathologies have the same functional signs: leucorrhoea or contact metrorrhagia. However in our patient, amenorrhea and weight loss that preceded the contact metrorrhagia were 
in favor of CTB. Also in these two pathologies, cervical speculum examination finds similar lesions: ulcerations, endocervical pseudopolyps, budding. Face to these common clinical signs, some biologycal abnormalities evoke CTB (reversal of the leukocyte formula, IDR positive to the tuberculin). ${ }^{6}$ In our case these biologycal abnormalities were effectively found. However PCR that is a modern and reliable technique for the diagnosis has not been considered in this case because of its unavailability in our context. ${ }^{1}$ Finally only the histologycal examination of the lesion allowed us to performed the confirmation diagnosis.

\section{Treatment and evolution}

The treatment of CTB is common to the other forms of tuberculosis: quadruple anti bacillary antibiotics for six months. However, the evolution of a CTB remains variable, and the cervical uterine synechia type aftermaths are common, often leading to infertility. ${ }^{4}$ In our patient the treatment has been successfully performed and the evolution was favourable without any aftermaths.

\section{CONCLUSION}

This observation, allowed us to find that a CTB which is an exceptional pathology exists in our country. It mainly affects young women living in modest conditions and is characterized by clinical signs similar to cervical cancer. The histology allows to establish the confirmation diagnosis and the HIV testing should be systematically performed in the affected patient. The treatment by antibacillary antibiotic therapy provides healing but the aftermaths are possibles.
Funding: No funding sources Conflict of interest: None declared

Ethical approval: Not required

\section{REFERENCES}

1. Mazza-Staldera J, Nicoda L, Janssens JP. Extrapulmonary tuberculosis. Rev Respiratory Dis. 2012;29:566-78.

2. Yang CT, Lee YH, Hsu GH. Tuberculosis of the uterine cervix. Taiwanese J Obstet Gynecol. 2012;51:449-51.

3. Bambara M, Konségré V, Ouattara A, Diallo AA, ZampaligréI, Lompo OG. Tuberculosis of the uterine cervix: about a case and literature review. Open J Obstet Gynecol. 2016;6:734-9.

4. Guié P, Koffi KE, Yao I, Tegnan J, N'guessan K, Touré CK, et al. Tuberculosis of the cervix: a case report. Afr J Pathol. 2007;6(1):29-32.

5. Dubernard G, Ansquer Y, Marcollet A, Walker F, Juras J, Madelenat P. Pseudo-tumoral tuberculosis of the cervix. Gynecol Obstet Fertil. 2003;31446-8.

6. Rakotomahenina H, Andrianampy HA, Rakotoson J L, Rabarijaona M, Solofomalala GD, Brun JL.

7. Genital tuberculosis discovered before infertility: first two cases observed at Fianarantsoa Teaching Hospital Madagascar. Med Sante Trop. 2015;25:3313.

Cite this article as: Dia JM, Saki TC, Kone Z, Koui S, Bohoussou PE, Diallo A, et al. Management of tuberculosis of the uterine cervix in the University Hospital Center of Treichville. Int J Reprod Contracept Obstet Gynecol 2018;7:739-41. 